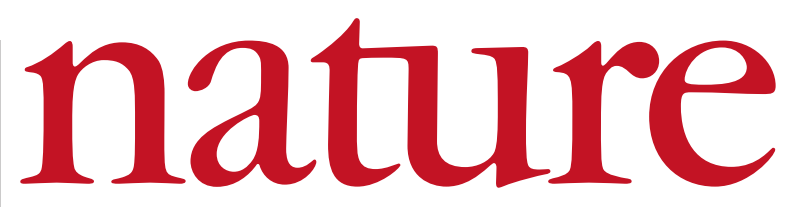

22 January 2004 Volume 427 Issue no 6972

\title{
Towards a German élite
}

A new government initiative to promote university development is a welcome attempt to stem the exodus of outstanding researchers from Germany. But it is also necessary to sustain deeper reform of the country's academic system.

L ast week an illustrious circle of ten top managers from science and industry assembled in Berlin to meet Chancellor Gerhard Schröder for an 'innovation dinner' in his office. He was hoping for impetus to his goal of enhancing the quality, competitiveness and worldwide recognition of Germany's research and higher-education system.

Whether or not the meeting served this purpose, its widespread publicity demonstrated Schröder's intent to tackle the country's pressing structural problems. That weakness in science and innovation is one of them is no secret but, unlike more obvious difficulties with the social-security systems, science policies seldom make headlines, and debate about reform had been muted.

That was before the phenomenal media coverage of Schröder's announcement, at the Social Democrats' New Year retreat in Weimar, of his intention to make the rusty research system ship-shape, and to create a number of German élite universities. Not surprisingly, the plan received a mixed response — the term 'élite' still stirs resentment in some German intellectuals. It is true that university excellence cannot be created by government decree, but students, researchers and science managers in Germany should be pleased that their needs have become the first major political issue of the year.

But what can Schröder actually do? Establishing a new élite university is the least likely option, and would be misguided - Germany's 100 or so research universities are not as weak as is sometimes alleged. There is no scientific powerhouse equivalent to, say, the Massachusetts Institute of Technology, but quite a few universities in Berlin, Munich, Heidelberg, Aachen, Tübingen and Göttingen, for example - can readily compete in one field or another.

If Schröder is willing to increase investment in science (and he seems to be serious about it), he should build on existing strengths, rather than try to conjure up a showpiece university out of nothing.
More importantly, he must use his authority in matters of general policy to create a legal and regulatory framework in which research and education can flourish, freed from anachronistic hierarchies and from the bureaucracies of the Länder (states).

The main defect of the German university system is that it is topheavy. Full professors are endowed with veritable kingdoms of power and privilege, whereas most young researchers and $\mathrm{PhD}$ students suffer ridiculously subordinate and dependent conditions - the exceptions only prove the rule. Young scientists who struggle through the system, usually on half-time contracts but expected to act as workhorses, risk ending up at 40 knocking on closed doors where, all too often, the academic appointment plans — set up by state officials, not by the universities - make no provision to employ them.

This, rather than the inferiority of German research per se, is the reason for the mass migration across the Atlantic of Germany's brightest minds. Competition in the United States may be even fiercer, but at least it has a culture of science that rewards commitment and merit, and where young investigators are more likely to be treated with due respect.

To be fair, Germany's academic culture is changing. The introduction three years ago of independent junior professorships is one example. Meanwhile, universities in Bavaria have been given some autonomy, and have begun to merge their respective strengths to the benefit of medical students in Munich, for example. Yet the Humboldt University in Berlin has to cut 80 of 300 faculty positions by 2009 , the average student-to-professor ratio is nightmarishly high, the right to select students is an exception rather than the rule, and the introduction of tuition fees is banned by law.

That awareness of these constraints has reached the highest levels of government is welcome. Schröder clearly intends to prioritize the health of academic science. Scientists should seize the moment.

\section{Back to the Moon}

\section{Despite scientific casualties, sending people to the Moon is politically the best way forward for science in the long term.}

$\mathrm{P}$ resident Bush's plan to steer NASA towards the Moon and Mars is, for now, more talk than action. The lunar landings, and most of the spending, will come long after he leaves office. Let's accept that his motives go beyond election-year grandstanding, however. Did he make the right decision?

Yes, with reservations. Having decided correctly to ground the shuttle and scale back investment on the space station, Bush choseprobably with an eye on US public opinion - to keep sending astronauts into space. The alternative was to cut NASA back to being a research-only agency. Scientists were fooling themselves if they thought that the money saved from the space shuttle would go on space telescopes. It would simply have disappeared.

The Moon is a useful, nearby place to find out whether human spaceflight still has a viable future. Arguments based on destiny or the 'human spirit' only go so far. In the end, astronauts need something to do out there. A small, 'tended' (rather than permanently occupied) lunar base can help settle the old, but never fully resolved, debate over sending humans or robots into space. The two will work together at first, just as in a modern factory on Earth. We can hope that NASA's twenty-first-century lunar exploration will advance the science of telerobotics in a meaningful way. If astronauts and machines are assigned work based solely on their merits and cost-effectiveness, we may see human visits to the base become less frequent as engineers learn to achieve the same tasks remotely. This evolution could be one of the new Moon programme's most valuable products, and could change the way we approach Mars exploration. Maybe when the time comes to send humans to Mars, we'll find that we don't need to.

But to reach that point, NASA should not prejudice the new Moon programme to favour astronauts over their robotic assistants. This will require clarity of purpose and honest decisions about engineering and funding priorities. Bush's plan calls on NASA to reinvent itself and break some ingrained bad habits. A tall order, but a good one. 